\title{
Lipocalin-2 to Creatinine Ratio Measurement
}

National Cancer Institute

\section{Source}

National Cancer Institute. Lipocalin-2 to Creatinine Ratio Measurement. NCI Thesaurus. Code C106540.

The determination of the ratio of lipocalin- 2 compared to creatinine present in a sample. The measurement may be expressed as a ratio or percentage. 